See discussions, stats, and author profiles for this publication at: https://www.researchgate.net/publication/333404535

\title{
Determining the best combination of MODIS data as input to ANN models for
} simulation of rainfall

Article in Archiv für Meteorologie Geophysik und Bioklimatologie Serie B · November 2019 DOI: 10.1007/s00704-019-02884-y

CITATION

1

2 authors, including:

Saeed Golian

National University of Ireland, Maynooth

51 PUBLICATIONS 722 CITATIONS

SEE PROFILE

Some of the authors of this publication are also working on these related projects:

Diffusive Wave View project

STNSRP View project 


\title{
Determining the best combination of MODIS data as input to ANN models for simulation of rainfall
}

\author{
Mohammad Khedmatkar Bolandakhtar ${ }^{1}$. Saeed Golian ${ }^{1}$
}

Received: 25 September 2018 / Accepted: 23 April 2019/Published online: 27 May 2019

(C) Springer-Verlag GmbH Austria, part of Springer Nature 2019

\begin{abstract}
In recent years, satellite data has been used to estimate precipitation with the aim of increasing the accuracy of rainfall spatial distribution especially at ungauged locations. In this research, the satellite data, including visible and infrared reflection data from the Moderate Resolution Imaging Spectroradiometer (MODIS) sensor and observation data, consists of rainfall records (10 years 2005-2015) from three synoptic stations in Semnan province, were used to simulate rainfall using an artificial neural network $(A N N)$ method. The network performance is evaluated through three performance criteria, i.e., correlation coefficient $(R)$, root mean square error (RMSE), and Nash-Sutcliffe (NS). Findings show that using a combination of visible reflection data of band 3 and infrared reelection data of bands 5,18, and 19 as input data results in better performance compared with other possible combinations. In this model, the values of $R$, NS, and RMSE for test period data were $0.93,0.81$, and 1.49 , respectively.
\end{abstract}

\section{Introduction}

Accurate measurements of rainfall with high spatial and temporal resolution are important for modeling surface currents, proper location of reservoirs, flood and drought prediction, water resource management, and agricultural projects (Jiang et al. 2012; Liu et al. 2017). Usually, rainfall data is taken from in situ observations, like rain gauges and climatology stations. The inadequate number and distribution of these stations and the lack of monitoring in a short term are the user's perpetual problems with rainfall data (Rana et al. 2015; Kidd et al. 2017). Recently, in order to overcome these issues, satellite data has been widely applied among hydrology researchers (Alijanian et al. 2017). This demand is crucial especially in developing countries such as Iran, where rainfall data is not available in many of its basins sufficiently (Moazami et al. 2013). Different methods and techniques have been developed to estimate rainfall using satellite data which use different indirect methods to estimate rainfall. These methods measure clouds' characteristics and also temperature in the upper cloud

Saeed Golian

s.golian@shahroodut.ac.ir

Mohammad Khedmatkar Bolandakhtar

Mohammad.akhtar6868@yahoo.com

1 Department of Civil Engineering, Shahrood University of Technology, Shahroud, Iran area to estimate precipitation (Barret and Martin 1981). Many studies have been carried out using visible (VIS) and infrared (IR) satellite data, and many algorithms have been developed to estimate precipitation using these data (Arkin and Meisner 1987; Adler and Negri 1988; Vicente et al. 1998; Todd et al. 1999; Anoop Kumar et al. 2011; Veerakachen and Raksapatcharawong 2015). One of the most shortcomings in these techniques is incorrect classification of rainy clouds so that cold clouds without rainfall in higher latitudes are often identified as rainy clouds, leading to false estimation of precipitation values (Scofield and Oliver 1977). Passive microwave (PMW) techniques measure rainfall more directly than VIS and IR data-based techniques; this is due to the ability of PMW data to penetrate in the clouds (Mishra et al. 2009). PMW data is provided by low-orbit arctic polar satellites, with low temporal resolution which has led to limitations in the use of these data (Behrangi et al. 2009). Also, in order to overcome the weakness of estimating precipitation from a single source, scientists considered the combination of VIS, IR, and PMW techniques (Todd et al. 2000; Kidd 2003). Many researchers used Tropical Rainfall Measuring Mission (TRMM) satellite data's to predict rainfall. These complementary methods, which use IR data, can fill the gap which is generated by using only PMW data in simulating rainfall fields (Simpson et al. 1996; Huffman et al. 2007; Kneis et al. 2014). Climate Prediction Center (CPC) morphing technique product global precipitation analyses at very high spatial and temporal resolution were developed to overcome the 
limitation of PMW-based precipitation products. This technique uses atmospheric motion vectors derived from GEO's IR data to propagate high-quality PMW precipitation estimates when updated PMW data are unavailable (Joyce et al. 2004; Ebert et al. 2007). Also, many studies have been carried out to estimate precipitation using the PERSIANN algorithm, an automated system for predicting remote sensing precipitation using artificial neural network (ANN) and TRMM satellite PMW data (Sorooshian et al. 2002; Zhou et al. 2008; Hsu and Sorooshian 2009, Liu et al. 2017). In recent years, scientists have been trying to calculate the precipitations of different areas of the planet by processing images of polar orbit satellites. The polar satellites and the sun have a low altitude, and due to their close proximity to the ground, they are precisely better than ground satellites (Hong et al. 2004). Nasrollahi et al. have identified rainfall regions from unpolluted areas in the USA using IR and MODIS brightness temperature (BT) data, besides CloudSat satellite observation data through an ANN method. Results show a remarkable improvement in the identification of no-rainfall areas (Nasrollahi et al. 2013). King et al. evaluated water vapor and precipitated water using the MODIS sensor. According to their studies, the general precipitation of rainwater from the MODIS sensor can be useful in predicting the distribution of rainfall patterns, the results of which exhibit significant moisture in near infrared (NIR) and thermal infrared (TIR) bands (King et al. 2002). Gao et al. developed an algorithm for extracting water vapor through NIR bands of the MODIS sensor. This algorithm relies on observations from NIR rays reflected by the surface and clouds (Gao and Kaufman 2003). Chen et al. have been able to determine the accuracy of total perceptible water data obtained from the MODIS sensor in the USA using the prediction model and meteorological research. It is notable that predicted perceptible water, which is extracted from IR data, is overestimated in a dry atmosphere while it shows underestimated prediction in a wet atmosphere (Chen et al. 2008). Yan et al. compared rainfall data using AMSRE microwave data and the brightness temperature of the $11-\mu \mathrm{m}$ bands from the MODIS sensor. The results indicate that rain forecasts from the MODIS and AMSRE sensors are very consistent with each other and provide the appropriate precision and similarity (Yan et al. 2005). Kapacchi et al. estimated the precipitation in the UK using the VIS and IR data of the polar satellite Terra combined with the ANN. Their research shows that the VIS and IR data in combination offer better results than individual TIR data (Kapacci and Conway 2005).

Due to the limited availability of water resources in Semnan province, accurate measurements of rainfall are important for proper management of water resources in the future. In this study, daily precipitation data from three synoptic stations during the 2005-2015 period and MODIS data are used to simulate precipitation using ANN. Using statistical assessment criteria, the proper architecture for ANN with the best combination of inputs to simulate the precipitation is proposed.

\section{Case study and data}

The study area is located in Semnan province including three synoptic stations at Shahroud, Damghan, and Semnan cities. Shahroud is located in $34^{\circ} 14^{\prime} \mathrm{N}$ and $54^{\circ} 33^{\prime} \mathrm{E}$ (Fig. 1). In addition, with an average altitude of $1349 \mathrm{~m}$ above sea level, it is located on the southern part of Alborz mountains. Based on long-term records, the average annual temperature and average annual precipitation are approximately $15{ }^{\circ} \mathrm{C}$ and $153 \mathrm{~mm}$, respectively. Damghan is located in $54^{\circ} 19^{\prime} \mathrm{E}$ and $36^{\circ} 9^{\prime} \mathrm{N}$ with an altitude of $1154 \mathrm{~m}$ above sea level. The average annual temperature and precipitation in Damghan are approximately $15{ }^{\circ} \mathrm{C}$ and $121 \mathrm{~mm}$, respectively. Finally, the Semnan is located in $53^{\circ} 23^{\prime} \mathrm{E}$ and $35^{\circ} 34^{\prime} \mathrm{N}$ with an average elevation of $1130 \mathrm{~m}$. Average annual temperature and precipitation are $18.4^{\circ} \mathrm{C}$ and $132 \mathrm{~mm}$, respectively.

In this study, 6-h rainfall during the statistical period of 2005-2015 was obtained as observational data from synoptic stations of Shahroud, Damghan, and Semnan, which comprise a total of 132 precipitation events. Besides the in situ data, images from MODIS, installed on the polar satellite Terra EOS, were also downloaded from http://reverb.echo.nasa. gov. The MODIS sensor can provide satellite images at a daily time interval, high spectral resolution (36 bands), and approximately suitable spatial resolution (from 250 to $1000 \mathrm{~m}$ ). Regarding the recorded daily rainfall data at synoptic stations of Shahroud, Damghan, and Semnan, images are available at 1-B level from MODIS with HDF format, which covers Shahroud, Damghan, and Semnan stations retrieved from the NASA website.

\section{Methodology}

In this study, we simulated rainfall precipitation using 6-h observational data from synoptic stations of Shahroud, Damghan, and Semnan during the period of 2015-2005 and MODIS sensor data through an artificial neural network. For this purpose, firstly, the images of the MODIS sensor were processed on the day of rainfall precipitation, and VIS and IR reflection data, emissivity of TIR bands 31 and 32, BT of TIR bands 31 and 32, and normalized difference vegetation index (NDVI) were extracted. Extracted data (either individually or in combination with each other) as input and daily observation data as output were fed to the artificial neural network. In order to evaluate the performance of ANN models, three statistical criteria, namely, correlation coefficient $(R)$, NashSutcliffe (NS), and root mean square error (RMSE) were used. 

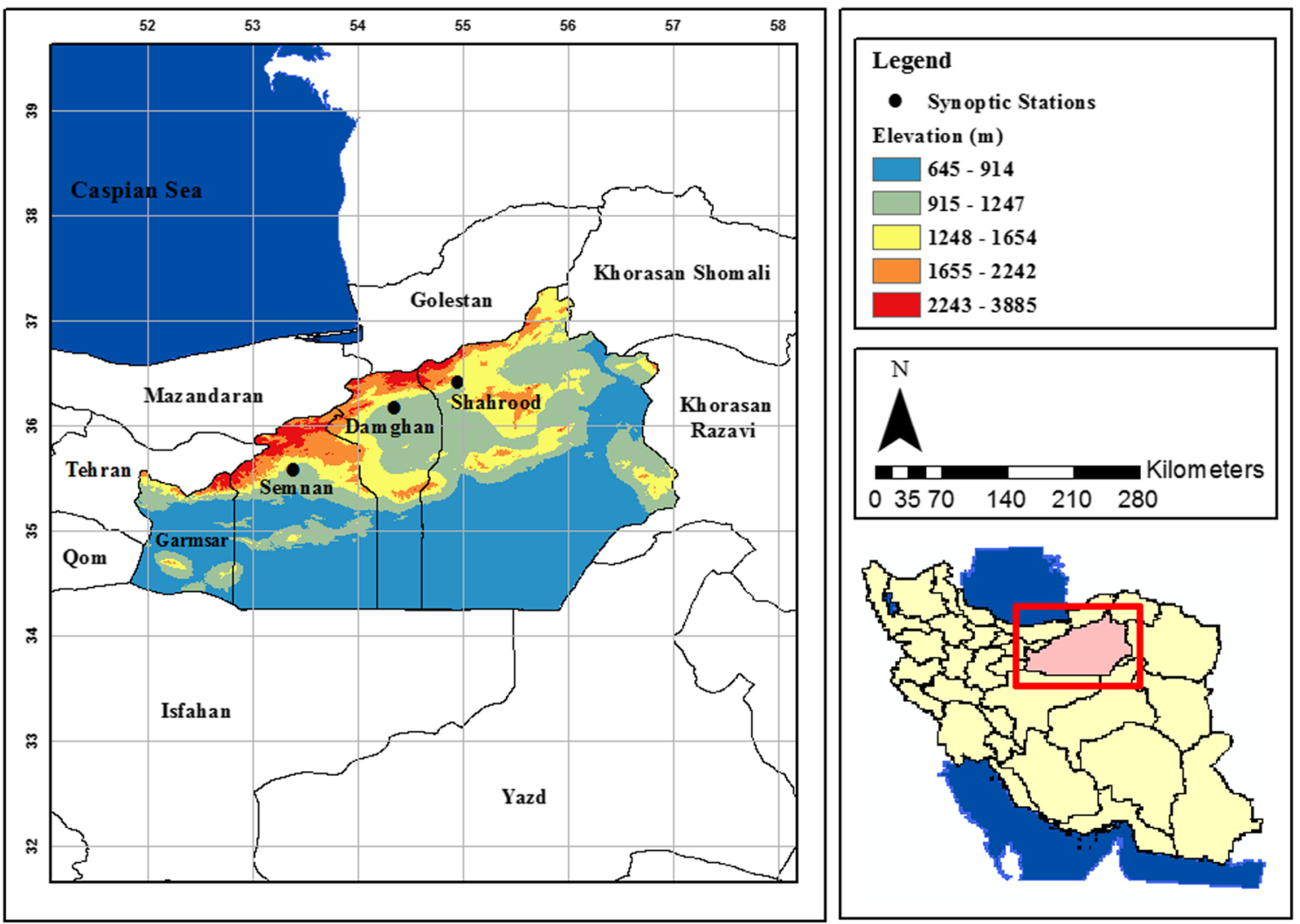

Fig. 1 Location of the case study and synoptic stations

Figure 2 depicts the proposed algorithm for data processing, analyzing and simulating precipitation using the ANN method.

In this research, for the purpose of managing and organizing satellite data, three steps, namely, of preprocessing, processing, and post processing of remote sensing data were applied as follows.

\subsection{Image preprocessing}

The first step in preprocessing satellite imagery is the geometric correction of images. The downloaded images are not georeferenced and should be geometrically corrected. For this purpose, the MCT plugin in ENVI 5.3 was used and satellite images were defined with the geographical coordinate system (WGS-84).

\subsection{Image processing}

In the processing of satellite imagery, the values of the radiance and emissivity parameters can be obtained from the MCT plugin in ENVI 5.3 software.

The NDVI is one of the most well-known, simplest, and most applicable plant herbal indicators (Kassa 1990). Although, from a theoretical point of view, the values of this index are in the range of -1 and +1 , but in practice, it has values less than +1 and more than -1 . The values of this index for a dense vegetation cover tend to be +1 , but clouds, snow, and water bodies have negative values. Bare soils and rocks, which have similar spectral responses in two bands, get values close to 0 (Kogan 1993).

The brightness temperature (BT) is the amount of electromagnetic radiation that is moving from the upper atmosphere to the satellite and is equivalent to the temperature of an equivalent black body. To calculate BT, the amount of reflection recorded in a pixel is converted to a light temperature factor as a digital number, and it is calculated using the Planck equation as follows:

$$
\mathrm{BT}=\frac{K_{2}}{\operatorname{Ln}\left(\frac{k_{1}}{L_{\gamma}}+1\right)}
$$

where BT is the brightness temperature in Kelvin, $L_{\gamma}$ is the spectral radiance $\left(\mathrm{W} \mathrm{m}^{-2}\right.$ steradian $\left.^{-1} \mu^{-1}\right), k_{1}$ is the first constant coefficient $\left(3.741775 \times 10^{-22} \mathrm{Wm}^{3} \mu^{-1}\right)$, and $K_{2}$ is the second constant coefficient $\left(0.0143877 \mathrm{~m}^{\top} \mathrm{K}\right)$.

\subsection{Image post processing}

After calculating required data including reflectance parameters, emission of thermal bands 31 and 32, NDVI, and BT of bands 31 and 32, maps of these data were extracted for the 
Fig. 2 Proposed flowchart for preparing data and its relation to rainfall simulation

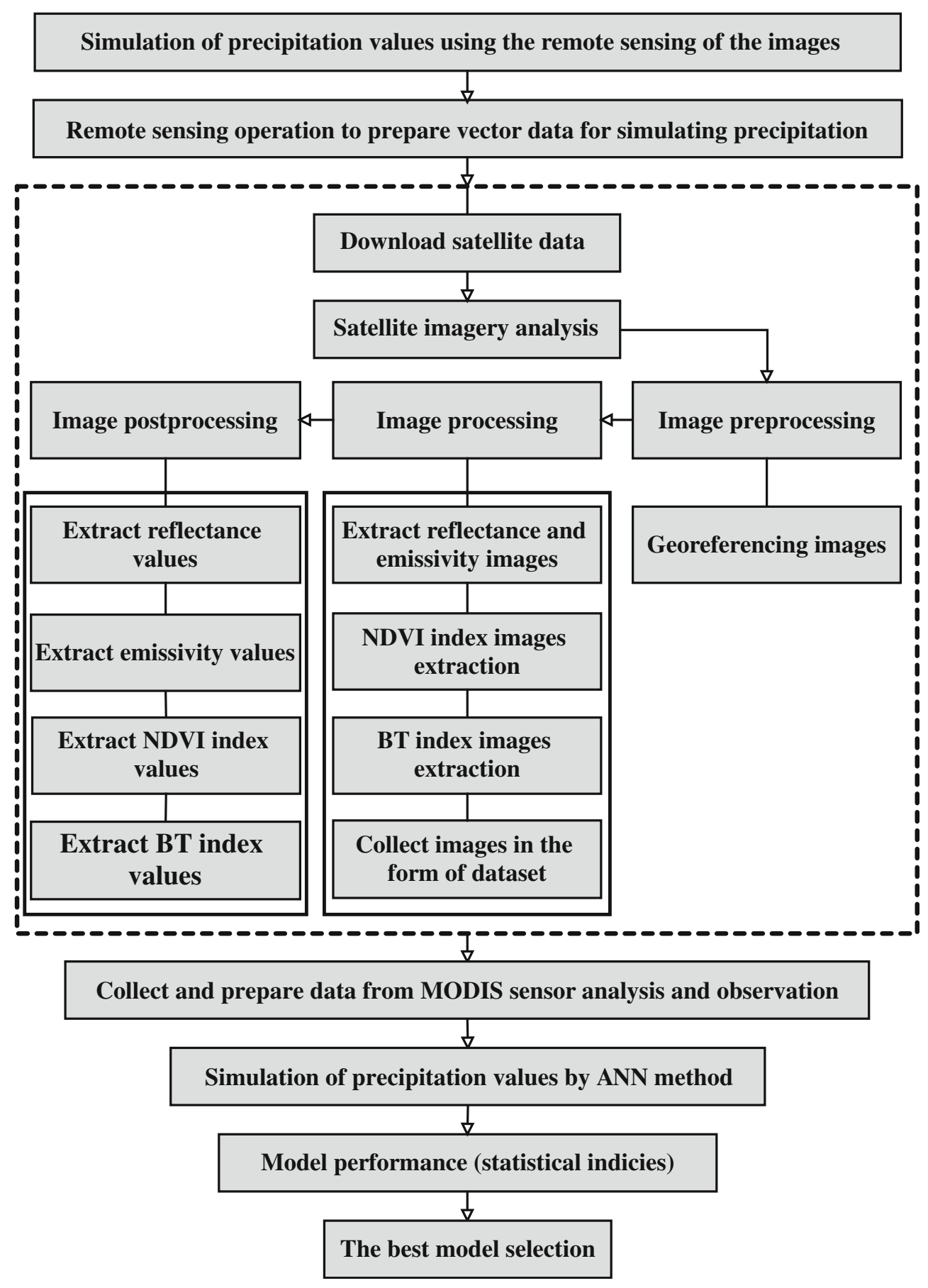

study areas. Data in which pixels with NAN data presented at the location of synoptic stations were removed from datasets.

Finally, required input-output datasets were built and fed into the ANN to simulate the precipitation. Table 1 contains different inputs considered in our study.

\subsection{Rainfall simulation using artificial neural network}

ANN is an appropriate solution for modeling nonlinear and complex phenomena (Noori et al. 2015). One of the most important parameters in the definition of an ANN is its architecture (Noori et al. 2011). ANN customary architecture is composed of three layers of neurons: input layer, hidden layer, and output layer (Haykin 1994). A neuron response is based on the weighted sum of all its inputs according to an activation function (Dehghani et al. 2014). Input neurons, or nodes, receive values of an instance of the input parameters that are fed to the network after being scaled into a numeric range that is efficient for calculations by the neural model. Outcomes to the output parameters for the instance under consideration are 
Table 1 Data extracted from images of the MODIS sensor to simulate rainfall

\begin{tabular}{llcl}
\hline Row & Data & Row & Data \\
\hline 1 & Visible band reflection 1 & 8 & Reflection of infrared band 19 \\
2 & Reflection of infrared band 2 & 9 & Reflection of infrared band 26 \\
3 & Visible band reflection 3 & 10 & Radiation infrared thermal band 31 \\
4 & Visible band reflection 4 & 11 & Radiation infrared thermal band 32 \\
5 & Reflection of infrared band 5 & 12 & The brightness temperature of band 31 \\
6 & Reflections of infrared band 7 & 13 & The brightness temperature of band 32 \\
7 & Reflections of infrared band 18 & 14 & Vegetative variation normalized \\
\hline
\end{tabular}

assigned by the output neurons. Hidden neurons connect the input neurons to the output neurons and provide nonlinearity to the network. Each neuron is connected to every neuron in adjacent layers by a connection weight, which determines the strength of the relationship between two connected neurons (Din and Smith 2002). Generally, neural networks are divided into two types, namely, feedforward and backforward. In most cases, feedforward networks considerably perform satisfactorily. Many researchers in the field of ANNs suggest that it is usually unnecessary to use more than one hidden layer in a multilayer feedforward network. A major reason for this is that intermediate cells not directly connected to output cells will have very small weight changes and will learn very slowly (Noori et al. 2010). To train neural networks, there are conventional training algorithms based on the layered perceptron structure. The most famous of these methods are the conjugate gradient and Levenberg-Marquette.

In this study, a feedforward neural network was used. Also, the Levenberg-Marquardt algorithm was utilized to train the network. The Levenberg-Marquardt algorithm was designed to approach second-order training speed without having to compute the Hessian matrix (Noori et al. 2011). First, the network was trained with a hidden layer, and in case of inappropriate performance, the number of layers was added. This also applies to the number of hidden layer neurons. In the first instance, the number of neurons was considered low and, if not converted to the optimal response, we increased them. In Table 2, the selected artificial neural network models include the best and worst models in terms of performance and some other important models, the results of which are debatable, and the combination of their input data are shown.

\subsection{Performance of artificial neural network}

In order to evaluate the performance of ANN and select the most satisfactory models, three statistical criteria, namely, correlation coefficient $(R)$, Nash-Sutcliffe (NS), and root mean square error (RMSE) were used.

\subsubsection{Correlation coefficient}

The correlation coefficient, denoted by $R$, is a measure of the strength and direction of a linear relationship between the simulated data and the observational data. The correlation coefficient can have a value between -1 and +1 . The closer the value is to +1 indicates a strong positive linear relationship between the simulated data and the observational data (Ratner 2009).

\subsubsection{Root mean square error}

The root mean square error (RMSE) accumulates the magnitudes of the differences between the simulated data and the
Table 2 ANN models with various combinations of input variables

\begin{tabular}{|c|c|}
\hline Model & Input combination \\
\hline ANN 1 & $\begin{array}{l}\text { Reflectance bands } 1,2,3,4,5,7,18,19 \text {, and 26; emissivity bands } 31 \text { and 32; NDVI; } \\
\text { and BT bands } 31 \text { and } 32\end{array}$ \\
\hline ANN 2 & Reflectance bands $1,2,3,4,5,7,18,19$, and 26 \\
\hline ANN 3 & BT bands 31 and 32; NDVI; and emissivity bands 31 and 32 \\
\hline ANN 4 & NDVI \\
\hline ANN 5 & BT bands 31 and 32 \\
\hline ANN 6 & Emissivity bands 31 and 32 \\
\hline ANN 7 & Reflectance bands 1,3 , and 4 \\
\hline ANN 8 & Reflectance bands 1, 3 and 4; BT bands 31 and 32; NDVI; and emissivity bands 31 and 32 \\
\hline ANN 9 & Reflectance bands 18 and 19 \\
\hline ANN 10 & Reflectance bands 18 and 19; BT bands 31 and 32; NDVI; and emissivity bands 31 and 32 \\
\hline ANN 11 & Reflectance bands $3,5,18$, and 19 \\
\hline
\end{tabular}


observational data for various times into a single measure of difference quantity. The value of RMSE is always positive and when it approaches zero, the efficiency of the model increases. In general, a lower RMSE is better than a higher one (KatiraieBoroujerdy et al. 2017)

\subsubsection{Nash-Sutcliffe}

The Nash-Sutcliffe efficiency index, denoted by NS, is a widely used and potentially reliable statistic for assessing the goodness of fit of hydrologic models (Nash and Sutcliffe 1970). Nash-Sutcliffe efficiency can range from $-\infty$ to 1 . Based on various studies in this field, including Gusman et al., the model has a good simulation model if the magnitude of the Nash-Sutcliffe coefficient is higher than 0.5 (Gassman et al. 2007).

\section{Results and discussion}

In this paper, an artificial neural network was used to simulate rainfall. For this purpose, the data extracted from the processing of MODIS images of the sensor as input and observation precipitation data as output were fed to the artificial neural network. In order to evaluate the performance of ANN models, the correlation coefficient, Nash-Sutcliffe, and root mean square error are used. Model performances based on statistical indices are shown in Table 3.

The scatterplots of the observational data against the simulated data using the artificial neural network for different models are shown in Fig. 3.

The ANN 1 model, which combines all data extracted from the analysis and processing of MODIS images (VIS and IR reflection data of 1 to $5,7,18,19$, and 26 bands; NDVI; BT of

Table 3 ANN performance based on different models of Table 2

\begin{tabular}{|c|c|c|c|c|c|c|}
\hline \multirow[t]{2}{*}{ Models } & \multicolumn{2}{|l|}{ Nash } & \multicolumn{2}{|l|}{$R$} & \multicolumn{2}{|c|}{ RMSE } \\
\hline & Train & Test & Train & Test & Train & Test \\
\hline ANN 1 & 0.93 & 0.44 & 0.96 & 0.76 & 0.76 & 2.58 \\
\hline ANN 2 & 0.99 & 0.54 & 0.99 & 0.78 & 0.78 & 2.28 \\
\hline ANN 3 & 0.69 & 0.44 & 0.83 & 0.70 & 0.70 & 2.64 \\
\hline ANN 4 & 0.71 & 0.59 & 0.84 & 0.82 & 0.82 & 2.76 \\
\hline ANN 5 & 0.87 & 0.47 & 0.93 & 0.81 & 0.81 & 1.68 \\
\hline ANN 6 & 0.73 & 0.45 & 0.85 & 0.70 & 0.70 & 2.12 \\
\hline ANN 7 & 0.83 & 0.54 & 0.91 & 0.75 & 0.75 & 2.16 \\
\hline ANN 8 & 0.83 & 0.46 & 0.91 & 0.73 & 0.73 & 2.59 \\
\hline ANN 9 & 0.87 & 0.68 & 0.93 & 0.91 & 0.91 & 1.96 \\
\hline ANN 10 & 0.71 & 0.54 & 0.97 & 0.77 & 0.77 & 2.8 \\
\hline ANN 11 & 0.94 & 0.81 & 0.97 & 0.93 & 0.93 & 1.49 \\
\hline
\end{tabular}

the TIR bands 31 and 32; and the emission of TIR 31 and 32 bands) as input to the artificial neural network, did not provide acceptable performance. The ANN 2 model, which used the reflection data of bands $1,2,3,4,5,7,18,19$, and 26 as input to the network, improved the network performance compared with the ANN 1 model, but did not provide satisfactory results. The ANN 3 model presented the weakest performance among all the examined models. Also, using NDVI data in the ANN 4 model, BT of the TIR bands 31 and 32 in the ANN 5 model, and emission of TIR 31 and 32 bands in the ANN 6 model as input data to the artificial neural network improved the network performance slightly. But the networks still showed poor performance. The results of the ANN 3, ANN 4, ANN 5, and ANN 6 models, which are based on the combination of emission, BT of 31 and 32 TIR bands, and also NDVI were not satisfactory and revealed poor model performance. By comparing the results of the ANN 1 to ANN 6 models, it is deduced that the emission data of 31 and 32 TIR bands, the BT of 31 and 32 TIR bands, and the NDVI have led to a decrease in the performance of the ANN models. Reflection data from VIS bands, when applied as input to the ANN (either individually or in combination with each other), reduce the performance of the network. Among the models that used VIS reflection data as input to the network, the ANN7 model provided the best result. In the ANN 7 model, only the reflective VIS data of bands 1,3, and 4 were used as input to the ANN. Among the IR reflection data (either individually or in combination with each other) that were used as input to the artificial neural network, the ANN 9 model showed the best performance. This model utilized the reflection IR data of bands 18 and 19 as input to the artificial neural network. It is notable that the 18 and 19 bands of MODIS are known as barrier water absorption bands. Also, the use of the NDVI, BT of the TIR bands 31 and 32, and emission of TIR 31 and 32 bands data in combination with the VIS reflection data of bands 1, 3, and 4 in the ANN8 model and the IR reflection data of bands 18 and 19 in the ANN 10 model as input to the artificial neural network led to a decrease in network performance compared with the ANN 7 and ANN 9 models. This can be explained by the poor performance of the NDVI, BT of the TIR bands 31 and 32, and the emission of TIR 31 and 32 bands data. The combination of IR reflection data and VIS reflection data significantly improved the performance of the artificial neural network. Various combinations of input data were investigated, and the ANN 11 model was the most efficient artificial neural network performance, so that among all the models reviewed in this study, this model presented the best performance. In this model, the combination of reflection data of band 3 from the VIS bands and the reflection data of bands 5, 18, and 19 from the IR portion of the electromagnetic spectrum was used as input to the neural network to simulate rainfall data. 


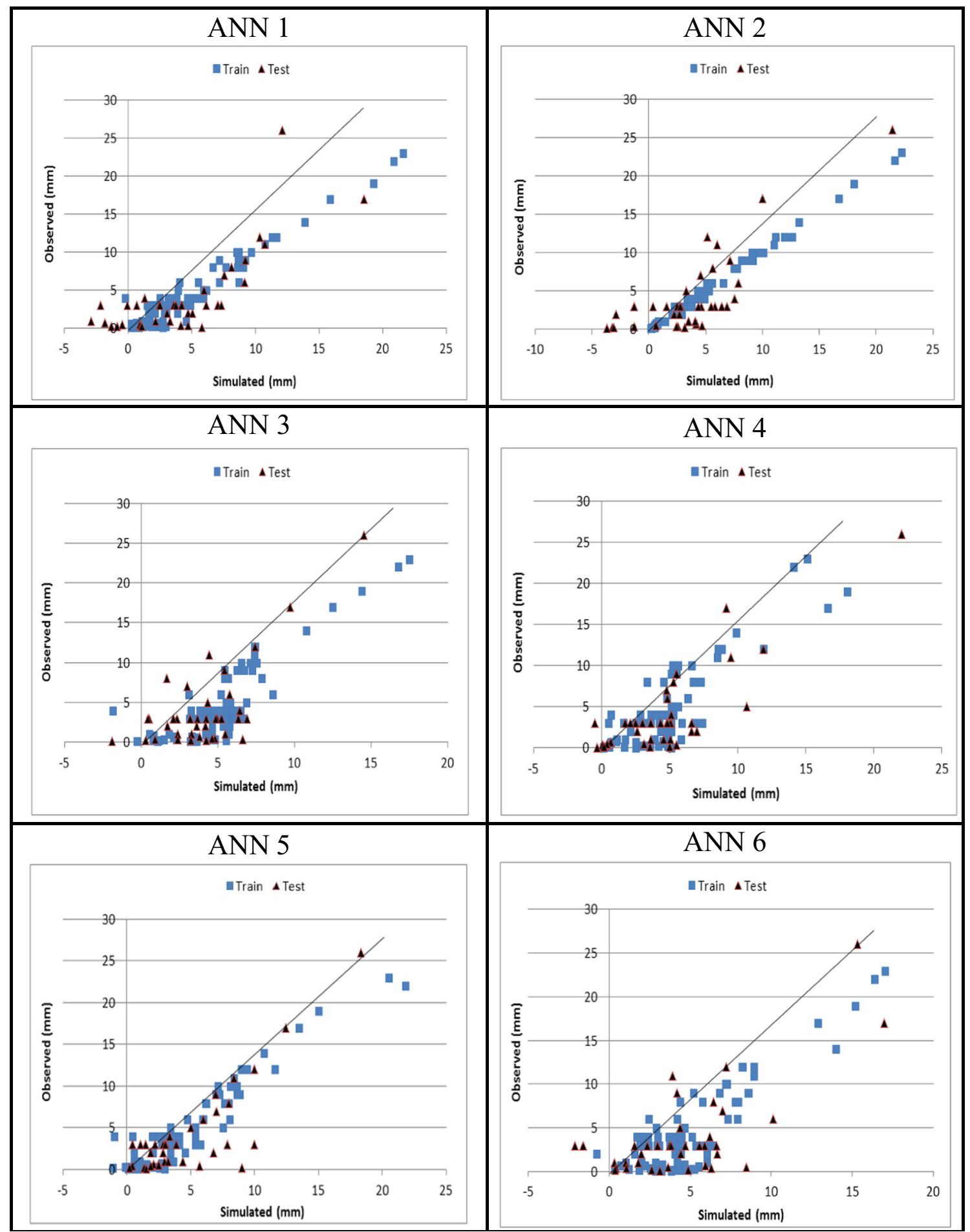

Fig. 3 Scatter plot of simulated vs. observed precipitation for different models

\section{Conclusion}

The purpose of this study was to simulate precipitation values using remote sensing data from MODIS images. In order to achieve a model with acceptable performance, different combinations of input data were fed to the ANN model. These input data include reflection bands of VIS and IR regions of the electromagnetic spectrum including bands 1 to $5,7,18$, 19, and 26, TIR emission bands 31 and 32, BT of bands 31 and 32, and NDVI. Also, 6-h observed precipitation data at synoptic stations of Shahroud, Damghan, and Semnan cities were used as model output. Finally, considering three 


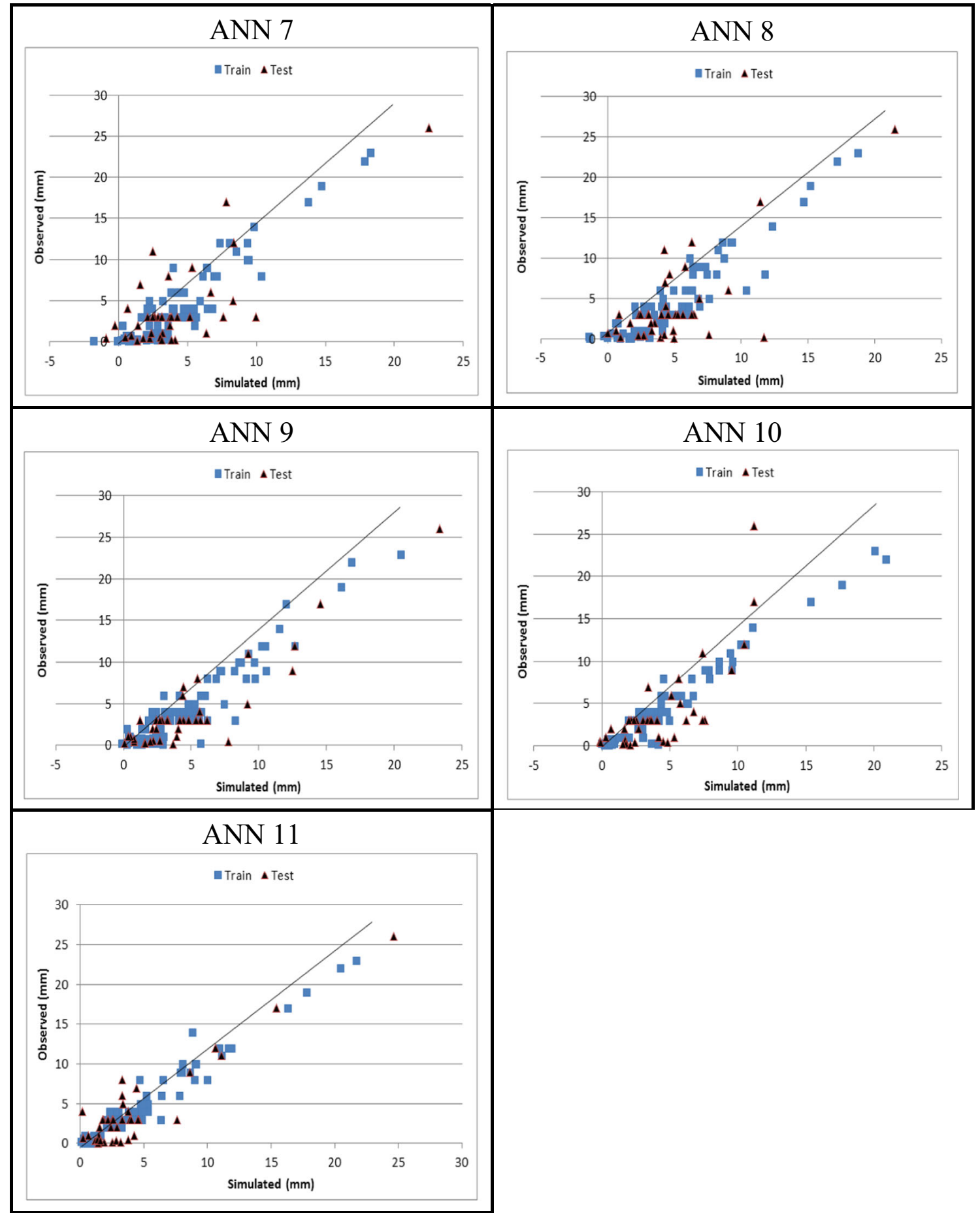

Fig. 3 (continued)

statistical criteria to assess the performance of ANN, the best combination of input data was determined to simulate precipitation. The most important results are as follow.

In this study, the weakest performance of artificial neural network is presented as a model that combines the NDVI, BT of the TIR bands 31 and 32, and TIR emission bands 31 and 32 data as input to the network. These data do not provide an acceptable performance either individually or in combination with each other. Also, their use in combination with VIS and IR reflection data led to degradation in model performance compared with models that only use VIS and IR reflection data (either individually or in combination with each other) as input to the network. With regard to the results of this research, it is concluded that the NDVI, BT of the TIR bands 31 and 32, and TIR emission bands 31 and 32 data were not suitable for simulating daily rainfall using the artificial neural 
network and could not provide acceptable results. Also, models that use VIS reflection data (either individually or in combination with each other) as input demonstrated poor performance, and simulated rainfall was not reliable. Among the various combinations of reflective IR data that were used to simulate rainfall, a model that combines bands 18 and 19 of the electromagnetic spectrum provided more accurate results. Reflective IR data in combination with VIS reflection data as input to the ANN model provided the best performance for rainfall simulation. Among the data used as input data to the ANN model, the combination of reflective data of band 3 from the VIS bands and the reflective data of bands 5, 18, and 19 from the IR portion of the electromagnetic spectrum was found to result in the best performance. This model presents acceptable performance for both training and test phases and can introduce reliable results for simulating precipitation over the study area.

\section{References}

Adler RF, Negri AJ (1988) A satellite infrared technique to estimate tropical convective and stratiform rainfall. J Appl Meteorol 27:30 51

Alijanian MA, Rakhshanderoo GR, Mishra AK, Dehghani M (2017) Evaluation of satellite rainfall climatology using CMPRPH, PERSIANN- CDR, PERSIANN, TRMM, MSWEP over Iran. Int J Climatol 37(14):4896-4914

Arkin PA, Meisner BN (1987) The relationship between large scale convective rainfall and cold cloud over the Western Hemisphere during 1982-84. Mon Weather Rev 115:51-74

Barrett EC, Martin DW (1981) The use of satellite data in rainfall monitoring. Academic Press, New York

Behrangi A, Hsu KL, Imam B, Sorooshian S (2009) PERSIANN-MSA: a precipitation estimation method from satellite-based multispectral analysis. Am Meteorol Soc 10:1414-1429

Capacci D, Conway BJ (2005) Delineation of precipitation areas from MIDS visible and infrared imageri with artificial neural networks. Meteor Appl 12:291-305

Chen SH, Zhao Z, Haase JS, Chen A, Vandenberghe F (2008) A study of the characteristics and assimilation of retrieved MODIS total precipitable water data in severe weather simulations. Mon Weather Rev 136:3608-3628

Dehghani M, Saghafian B, Nsiri Sleh F, Farokh Nia A, Noori R (2014) Uncertainty analysis of streamflow drought forecast using artificial neural networks and Monte-Carlo simulation. Int J Climatol 34: $1169-1180$

Din AGE, Smith DW (2002) A neural network model to predict the wastewater inflow incorporating rainfall events. Water Res 36: 1115-1126

Ebert EE, Janowiak JE, Kidd C (2007) Comparison of near-real-time precipitation estimates from satellite observations and numerical models. Bull Am Meteorol Soc 88(1):47-64

Gao BC, Kaufman YJ (2003) Water vapor retrievals using Moderat Resolution Imaging Spectroradiometer (MODIS) near infrared channels. J Geophys Res Atmos 108(13):4389-4399

Gassman PW, Reyes MR, Green CH, Arnold JG (2007) The soil and water assessment tool: historical development, applications, and future research directions. Trans ASABE 50(4):1211-1250
Haykin S (1994) A comprehensive foundation, 2nd edn. Macmillan, New York

Hong Y, Hsu KL, Sorooshian S, Gao X (2004) Precipitation estimation from remotely sensed imagery using artificial neural network cloud classification system. J Appl Meteorol 43(12):1434-1453

Hsu KL, Sorooshian S (2009) Satellite-based precipitation measurement using PERSIANN system. Hydrol Model Water Cycle 27-48

Huffman G, Adler R, Bolvin D, Gu G, Nelkin E, Bowman K, Stocker E, Wolff D (2007) The TRMM multi-satellite precipitation analysis: quasi-global, multiyear, combined-sensor precipitation estimates at fine scales. J Hydrometeorol 8:38-55

Jiang S, Ren L, Hong Y, Yong B, Yang X, Yuan F, Ma M (2012) Evaluation of multi- satellite precipitation products with a dense rain gauge network and optimally merging their simulated hydrological flows using the Bayesian model averaging method. J Hydrol 452453:213-225

Joyce RJ, Janowiak JE, Arkin PA, Xie P (2004) CMORPH: a method that produces global precipitation estimates from passive microwave and infrared data at high spatial and temporal resolution. J Hydrometeorol 5:487-503

Kassa A (1990) Drought risk monitoring for Sudan using NDVI. A Dissertation Submitted to the University College London

Katiraie-Boroujerdy PS, Akbari Asanjan A, Hsu K, Sorooshian S (2017) Intercomparison of PERSIANN-CDR and TRMM-3B42V7 precipitation estimates at monthly and daily time scales. Atmos Res 193: 36-49

Kidd C (2003) Satellite rainfall estimation using combined passive microwave and infrared algorithms. J Hydrometeorol 4:1088-1104

Kidd C, Becker A, Huffman GI, Muller CL, Joe P, Skofronick- Jackson G, Kirschbaum DB (2017) So, how much of the earth surface is covered by rain gauge? Bull Am Meteorol Soc 98:69-78

King MD. Menzel WP. Kaufman YJ, Tanre D. Gao BC. Platnick S, Ackerman SA, Remer LA, Pincus R, Hubanks PA (2002) Cloud and aerosol properties, precipitable water, and profiles of temperature and water vapor from MODIS. IEEE Trans Geosci Remote Sens $1-44$

Kneis D, Chatterjee C, Singh R (2014) Evaluation of TRMM rainfall estimates over a large Indian river basin (Mahanadi). Hydrol Earth Syst Sci 18:2493-2502

Kogan FN (1993) United States droughts of late 1980's as seen by NOAA polar orbiting satellite. Int Geosci Remote Sens Symp 1:197-199

Liu X, Yang T, Hsu K, Liu C, Sorooshian S (2017) Evaluating the stream flow simulation capability of PERSIANN-CDR daily rainfall products in two river basins on the Tibetan Plateau. Hydrol Earth Syst Sci 21:169-181

Mishra M, Gairola RM, Varma AK, Agarwal VK (2009) Study of intense rainfall events over India using Kalpana- IR and TRMM- precipitation in radar observation. J Curr Sci 97(5):689-695

Mishra A, Gairola RM, Varma AK, Agrawal VK (2011) Improved rainfall estimation over the Indian region using satellite infrared techniques. In: Adv Space Res, vol 48, pp 49-55

Moazami S, Golian S, Kavianpour MR, Hong Y (2013) Comparison PERSIANN and V7 TRMM multisatellite precipitation analysis (TMPA) products with rain gauge data over Iran. Int J Remote Sens 34(22):8156-8171

Nash JE, Sutcliffe J (1970) River flow forecasting through conceptual models, part 1, a discussion of principles. J Hydrol 10:282-290

Nasrollahi N, Hsu K, Sorooshian S (2013) An artificial neural network model to reduce false alarms in satellite precipitation products using MODIS and CloudSat observations. J Hydrometeorol 14:18721883

Noori R, Khakpour A, Omidvar B, Farokhnia A (2010) Comparison of ANN and principal component analysis- multivariate linear regression models for predicting the river flow based on developed discrepancy ratio statistic. Exp Syst Appl 37:5856-5862 
Noori R, Karbassi AR, Mehdizadeh H, Vesali-Naseh M, Sabahi MS (2011) A framework development for predicting the longitudinal dispersion coefficient in natural streams using an artificial neural network. Environ Prog Sustain Energy 30:439-449

Noori R, Deng Z, Kiaghadi A, Torabi Kachoosangi F (2015) How reliable are ANN, ANFIS, and SVM techniques for predicting longitudinal dispersion coefficient in natural rivers? J Hydraul Eng 142(1): 04015039-1-04015039-8

Rana S, McGregor J, Renwick J (2015) Precipitation seasonality over the Indian subcontinent: an evaluation of gauge, reanalysis and satellite retrievals. J Hydrometeorol 16(2):631-651

Ratner B (2009) The correlation coefficient: its values rang between +1 / -1 , or do they? J Target Meas Anal 17:139-142

Scofield RA, Oliver VJ (1977) A scheme for estimating convective rainfall from satellite imagery. NOAA tech, memo, dept. of commerce, Washington, D.C., p 47

Simpson J, Kummerow C, Tao WK, Adler RF (1996) On the Tropical Rainfall Measuring Mission (TRMM). Meteorog Atmos Phys 60: $19-36$

Sorooshian S, Gao X, Hsu K, Maddox RA, Hong Y, Gupta HV, Imam B (2002) Diurnal variability of tropical rainfall retrieved from combined GOES and TRMM satellite information, vol 15. Am Meteorol Soc, pp 983-1001

Todd MC, Barrett EC, Beaumont MJ, Bellerby TJ (1999) Estimation of daily rainfall over the upper Nile river basin using a continuously calibrated satellite infrared technique. Meteorol Appl 6:201-210
Todd MC, Kidd C, Kniveton D, Bellerby TJ (2000) A combined satellite infrared and passive microwave technique for estimation of smallscale rainfall. J Atmos Ocean Technol 18:742-755

Veerakachen W, Raksapatcharawong M (2015) Rainfall estimation for real time flood monitoring using geostationary meteorological satellite data. Space Res 56:1139-1145

Vicente GA, Scofield R, Menzel A, Paul A (1998) The operation of GOES infrared rainfall estimation techniques. Am Meteorol Soc 70:24-33

Yan H, Wang J, Wu M, Zhou W (2005) A comparison of MODIS infrared technique and AMSR-E microwave technique for overland rainfall estimates in midlatitude. IEEE Int 5:5116-5118

Zhou T, Yu R, Chen H, Dai A, Pan Y (2008) Summer precipitation frequency, intensity, and diurnal cycle over China: a comparison of satellite data with rain gauge observations. Am Meteorol Soc 21:3997-4010

Publisher's note Springer Nature remains neutral with regard to jurisdictional claims in published maps and institutional affiliations. 